\title{
Picornavirus-like Particles In The Lungs Of a Patient With Severe Pneumonia.
}

\author{
L. V. S. Asher*, L. Pearse**, B.P. Petruccelli*** \\ *Division of Pathology, Walter Reed Army Institute of Research, Silver Spring, \\ Maryland 20910-7500 \\ ** Armed Forces Institute of Pathology, Washington, DC \\ ***US Army Center for Health Promotion and Preventive Medicine, Aberdeen Proving \\ Ground, Maryland
}

The patient was one of the probable cases of acute eosinophilic pneumonia (AEP) that was diagnosed in military personnel deployed in and around Iraq from March 2003 through March 2004 [1].

He was a 20 -year-old male, in good health and a non-smoker prior to deployment. He began smoking cigarettes shortly after he arrived in Kuwait. After his unit was moved to Baghdad he was working as a heavy machine operator moving loads of gravel. After about a week he complained about muscle pain in his chest, cough and shortness of breath. He was transferred to the hospital where he was diagnosed with pneumonia and acute respiratory distress syndrome (ARDS). Patient was treated with multiple antibiotics, but his condition quickly deteriorated, he developed renal and liver failure and died two weeks from the onset of illness.

Post-mortem examination of the lungs revealed diffuse alveolar edema with fine granular precipitates of plasma proteins and multifocal alveolar hemorrhages mixed with fibrin, indicating diffuse alveolar damage. Numerous alveolar macrophages, epithelial cells and leukocytes contained brown-black cytoplasmic inclusions. In addition, some alveolar epithelial cells had clusters of small non-enveloped picornavirus-like particles (VLPs), measuring about $30 \mathrm{~nm}$ in diameter. Aggregates of VLPs in crystalline arrays were also seen in alveolar space outside of epithelial cells.

Numerous cocco-bacilli were also present in alveoli; they were surrounded by a narrow clear space suggestive of a capsule. Klebsiella pneumoniae was isolated from most of the tissues post-mortem.

The identity of virus-like particles needs to be confirmed. Although it is unusual to consider picornavirus as a possible etiologic agent for pneumonia and ARDS in adults, it cannot be entirely excluded, as rhinoviruses (in a group of picornaviridae) had been associated with pneumonia in children and immunocompromized patients [2].

\section{References:}

1. A.F. Shorr et al., JAMA, (2004) 292, 2997-3005.

2. F.G. Hayden. Rev. Med. Virol. (2004) 1, 17-31. 


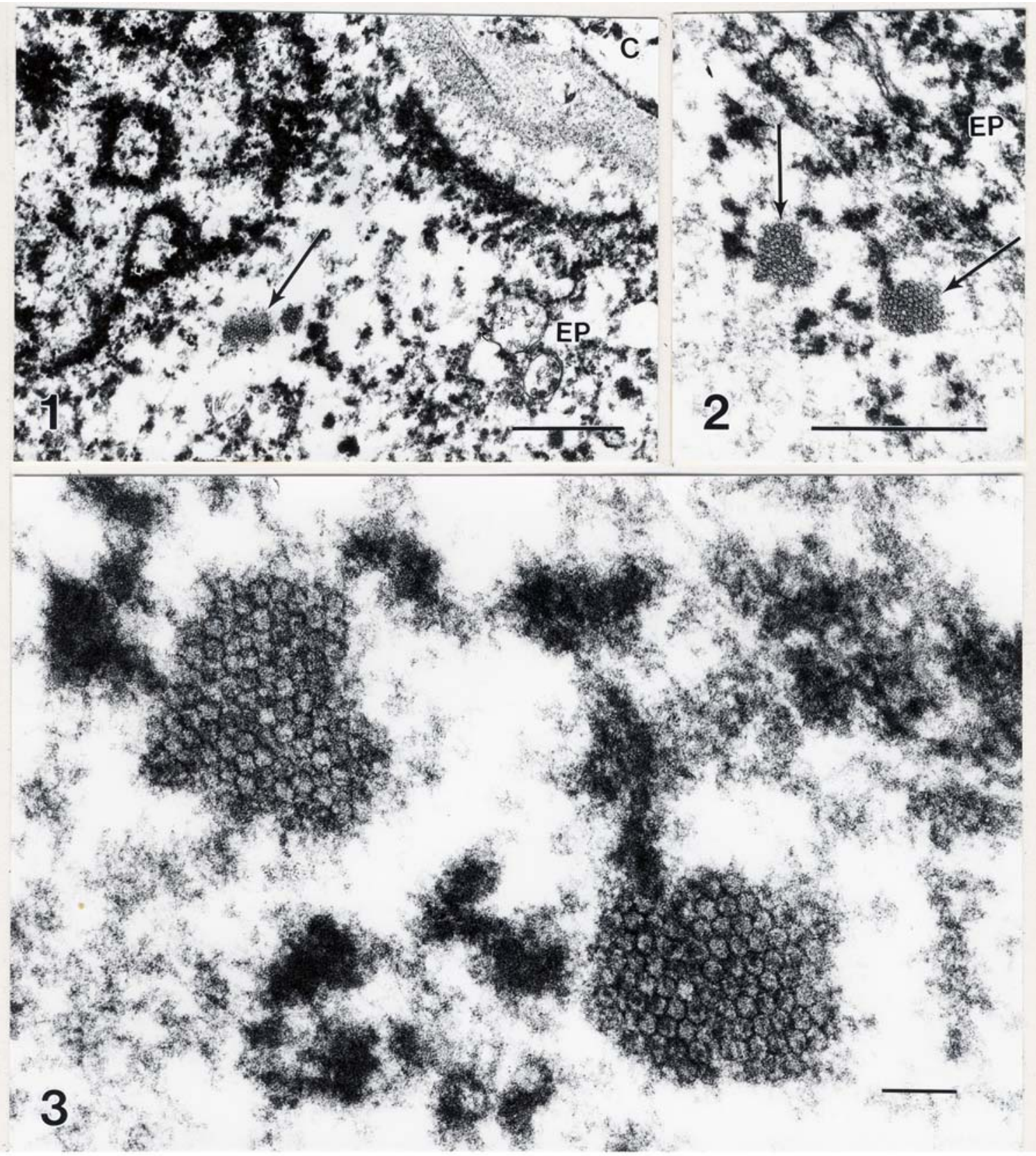

Fig. 1. VLPs in the cytoplasm of an alveolar epithelial cell (arrow).

$\mathrm{C}$, capillary lumen, Ep, epithelial cell. Bar $=1 \mu \mathrm{m}$.

Fig. 2. VLPs in alveoli, outside of an epithelial cell. Bar $=1 \mu \mathrm{m}$.

Fig. 3. Enlargement of Fig.2 showing crystalline arrangement of VLPs.

Bar $=100 \mathrm{~nm}$ 